Available online on 15.09.2019 at http://jddtonline.info
OC 2011-18, publisher andlicensee JDDT, This is an Open Access article which permits unrestricted
non-commercial use, provided the original work is properly cited

Open ${ }_{\text {Access }}$

Case Report

\title{
Individualized Homeopathic Treatment: Better Option in Management of Psoriasis
}

\author{
Dr. Hiralal H Agarwal ${ }^{*}$, Dr. Vilas L Jahagirdar², Dr. Zeenat Fatima Faroouqi3 ${ }^{3}$, Dr. Onkar Kelkar4 \\ ${ }^{1}$ Homeopathic Physician, Shri-Ram Clinic, Solapur, Maharashtra, India.
}

${ }_{2}^{2}$ Retired Dean, Government Medical College, Miraj, Maharashtra, India.

${ }_{3}$ Homeopathic Physician \& Clinical Counseller, Shifa Homeopathic Clinic, Solapur, Maharashtra, India.

${ }_{4}^{4}$ Homeopathic Physician, Onkar's Homeo Clinic, Solapur, Maharashtra, India.

\begin{abstract}
Psoriasis Vulgaris is a cutaneous, inflammatory disease manifested by aberrant immune response mediated by T-lymphocytes. The disease is characterized by keratinocyte hyperproliferation, improper differentiation, angiogenesis, and dermic vasodilatation. Psoriasis significantly affects the quality of the patient's life due to emotional stress. Sometimes the patient may feel progressive mental depression and in turn seriously affecting his/her family surrounding. The treatment approaches towards the successful management of psoriasis deserves consideration since the incidence of the disease is increasing nowadays. Treating physicians should share their clinical experiences on the global platform to benefit the patients effectively. Considering this aspect the present article describes some case studies of the management of Psoriasis with the help of homeopathic medicines.
\end{abstract}

Keywords: Homeopathy, Psoriasis, Dermatology, Skin Disease.

Article Info: Received 11 July 2019; Review Completed 20 August 2019; Accepted 23 August 2019; Available online 15 Sep 2019

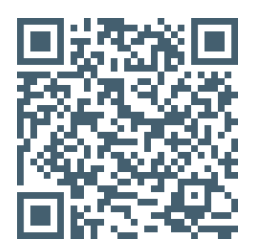

\section{Cite this article as:}

Agarwal HH, Jahagirdar VL, Faroouqi ZF, Kelkar O, Individualized Homeopathic Treatment: Better Option in Management of Psoriasis. , Journal of Drug Delivery and Therapeutics. 2019; 9(5):151-153

http://dx.doi.org/10.22270/jddt.v9i5.3539

*Address f or Correspondence:

Dr. Hiralal H Agarwal, Homeopathic Physician, Shri-Ram Clinic, 185, Modi, Solapur, Maharashtra, India.

\section{INTRODUCTION}

Psoriasis is a common skin disease even identified in the mummified bodies, affecting the global population for many years. The disease involves the infiltration of cells of dermis and epidermis resulting in inflammatory lesion affecting the skin surface [1-4]. Visibly red, raised and scaly plaque-like lesions are major clinical signs of the disease. The disease can be classified based on its severity as mild, moderate and severe psoriasis. Body Surface Area (BSA), Psoriasis Area Severity Index (PASI) and Dermatology Life Quality Index (DLQI) are used for scoring of different patterns to classify psoriasis based on disease severity (Figure 1). The initial (mild) stage of the disease involves only $2 \%$ of the skin surface, while disease representation between 2 to $10 \%$ of the skin is described as a moderate form of the disease and representation over $10 \%$ of the skin is described as severe psoriasis [5-7]. "Psoriasis Area Severity Index" plays a vital role in the evaluation of the disease severity and monitoring of thetreatment progress.

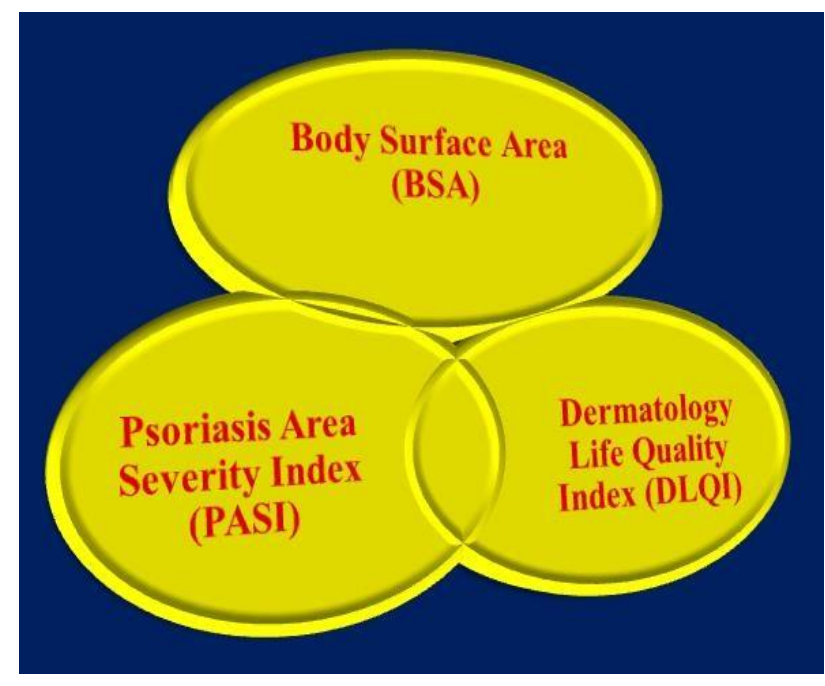

Figure 1: Scoring pattern defining measurement severity of Psoriasis. 
The Prototype symptoms and signs of the disease can be listed as follows:

Red raised patches on the affected skin surfaces.

Plaques.

Skin becomes dry and may get cracked.

Soreness, itching and burning sensation.

Painful and swollenjoints.

Sometimes oozing discharge may be seen from inflamed patches.

The exact causes of psoriasis are unknown however there are some triggering factors which may initiate pathogenesis of psoriasis, these factors are as follows:
* Hormonal changes
* Alcohol and smoking
* Stress and predisposing geneticfactors
* Environmental factors and climatic diversity
* Skin injury or insectbites
* Infections and autoimmune disorders

\section{MATERIALS AND METHODS}

\section{Collection of cases:}

Four patients of Psoriasis among the patients attending Shree Ram Homeopathic Clinic and Research Center were registered in OPD, investigated and treated are presented here. The selection of patients was done as per the following criteria:

\section{Inclusion Criteria:}

\section{Patients from age group 15-6o years}

Either sex

$\square$ Presenting prototype symptoms of Psoriasis

Irrespective of socio-economic status
Patients did not possess other known chronic illness.

\section{Exclusion Criteria}

Patients actively taking other medication especially Ayurveda or allopathic drugs

$\square$ Patients of psoriasis but not interested to participate in this study

$\square \quad$ Children below 15 years and elderly above 60 years

$\square$ Patients having only initial manifestation of disease, however not resembling prototype symptoms of psoriasis

\section{CASES STUDIES}

Case 1: Retired policeman, age about 6o years having severe psoriatic patches was not benefited by medication received earlier. It was found that the disease manifestation initiated just after the suicidal death of his daughter. He overcame the grief of her death but he had developed apprehension that he has lost his social position and therefore cannot go out to mix in the society. He kept himself isolated from society and avoided social interaction after the incident.

We evaluated clinical case considering all his physical and mental status. Nux Vomica was selected and given in $1 \mathrm{M}$ potency three doses; the study observed appreciable reduction in patches severity after prescribing Nux Vomica. However after sometime relapses of clinical symptoms appeared due to the additional stressful family conditions, then Staphysagria was given to him and it was found that use of Staphysagria not only stopped relapses but also cured him up to greatextent.

The photographs of this case before and after treatment are presented in Figure2.

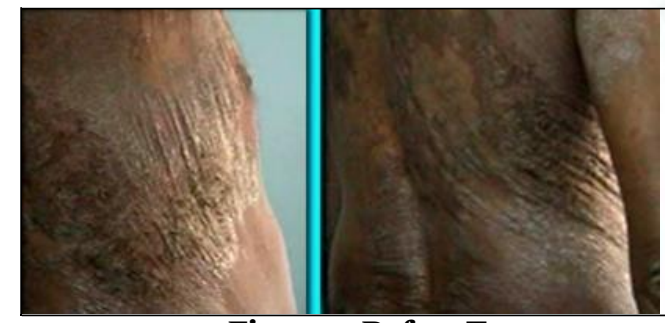

Figure2: BeforeTreatment

Case 2: The patient was a 55-year-old female, with Palmo Plantar Psoriasis for more than 7 years and had earlier received treatment from many other physicians but did not get benefited. After detailed interrogation and caseanalysis patient was prescribed Arsenic Alba as a homeopathic remedy. Arsenic Alba potencies from $30 \mathrm{C}$ to $10 \mathrm{M}$ offered beneficial effects during the course of one year long

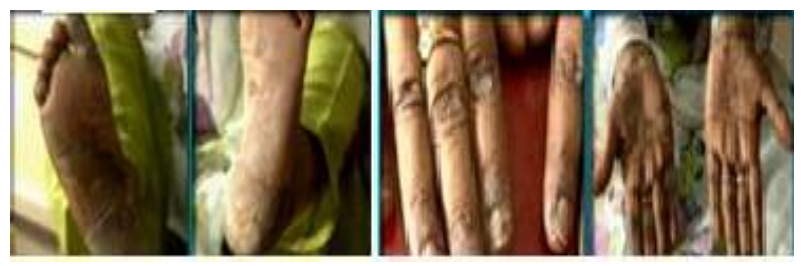

Figure3: BeforeTreatment

Case-3: A 40-year young anesthetic physician from civil hospital; was referred for his increasing psoriatic patches all over the body which had just started for the last 6 months. After detail case taking it was found that he had extreme stress about pursuing his anesthesia career and also from

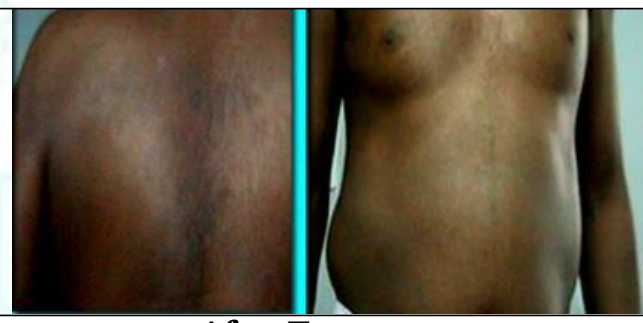

After Treatment

treatment. The photographs of this case before and after treatment are presented in Figure 3. Arsenic Albarelieved all her symptoms like; anxiety, stringiness, itching, and insecurity. Arsenic Alba was selected because of her characteristic mental features of anxiety, insecurity, and stringiness.

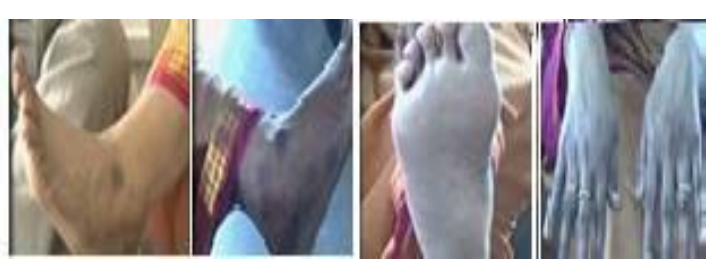

\section{After Treatment}

work load in hospital. He was living away from family. Detail case indicated Lycopodium as his remedy \& was given in $200 \& 1 \mathrm{M}$ potencies which cleared all his patches as shown in Figure 4. Lycopodium was selected on his physical symptoms like craving for sweets, desire for hot food and hot drinks. 
Recurrent throat infections and getting different mental levels of anger easily along with past
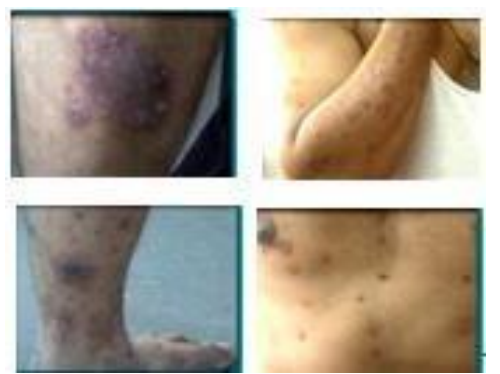

Figure4: Before Treatment

Case 4: The young male patient aged around 35 years came with psoriatic patches all over the body and suffered from sleeplessness due to itching problem. The patient followed an irregular lifestyle pattern and inconsistent timing of meal. The patient complained that he couldn't tolerate hunger and was used to having regular consumption of fish and chicken. The patient was found to be mentally stressed and fastidious may be due to his professional work. Nux Vomica was
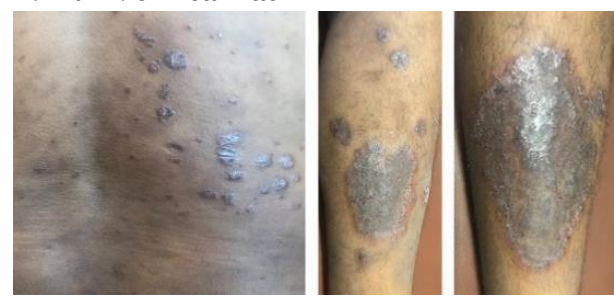

Figure5: BeforeTreatment

\section{DISCUSSION}

This study observed that "Aberrant Individual Immunity" and mostly complicated by disturbed psyche plays a vital role in triggering the disease pathogenesis while certain other factors enhance disease severity like; stress, diet, sedentary lifestyle, work pressure, and environmental factors. This study further observed that the patient due to this disease condition feels socially depressed and has an immense lack of confidence, which improved very well after treatment. In the above study, it was observed that the relapses were seen in cases with low immunity and during the period of emotional stress. The study believes that long term treatment with homeopathic medicine offers an appreciable response with reduction in relapses severity and improved sense of general well being.

\section{CONCLUSION}

The case studies concluded that there is a very positive, effective and long term disease-free situation that can be achieved with "Individualized homeopathic treatment". Not only there is an early and fast general feeling of wellbeing their social position and confidence is also restored. Appreciable and good control of mental and emotional status was seen after the correct homeopathic remedy thereby reducing the relapses period and intensity. The incidence or prevalence of disease can also be reduced by supplementation of healthy diet and change in lifestyle. The avoidance of sedentary lifestyle and conduction of a disciplined daily regimen is found essential for combating many diseases including Psoriasis. The approach that is history of renal stones was also noted.
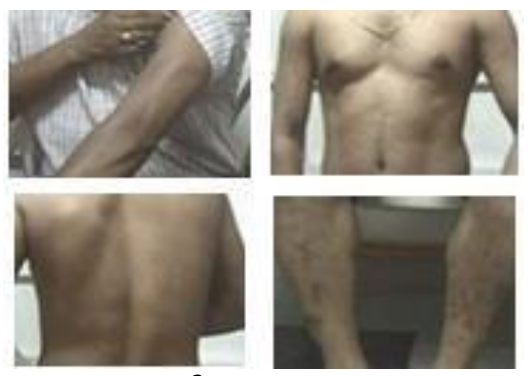

After Treatment

prescribed to him and reduction in patch thickness was observed but itching increased, relapse of patches was also observed in dry and cold weather. Nux Vomica was repeated in the same potency and long term treatment provided the best relief with no incidence of relapse.

The photographs of this case before and after treatment presented in Figure 5.
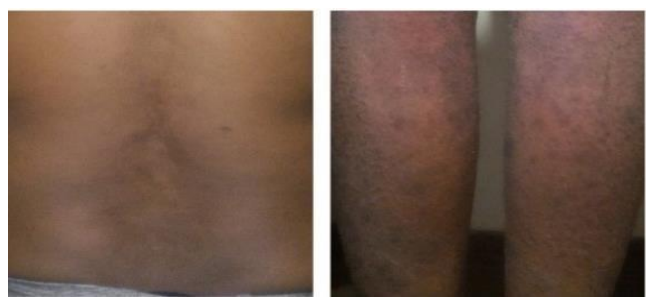

After Treatment

useful in eliminating psoriasis symptoms or minimizes the risk of the recurrence needs to be optimized. Homeopathic fraternity should conduct similar studies and implement public awareness campaigns.

\section{Financial support \& sponsorship: NIL}

\section{Conflicts of interest: No conflicts of interest}

Statement of Ethics: The patients provided willful verbal consent during the course of treatment.

\section{REFERENCES}

1. World Psoriasis Day 2016 General Summary. Bromma, Sweden: International Federation of Psoriasis Associations; 2016.

2. Fernandes, A, Martins Gomes, C, Santini, A, Silva, A, Souto, E. Psoriasis Vulgaris-pathophysiology of the disease and its classical treatment versus new drug delivery systems. Design of Nanostructures for Versatile Therapeutic Applications. 2018; 379-406.

3. Chandra, A, Ray, A, Senapati, S, Chatterjee, R. Genetic and epigenetic basis of psoriasis pathogenesis. Mol Immunol. 2015; 64 (2): 313,323.

4. Dr. Samuel Hahnemann Organon of Medicine. B Jain Publishers; 2009.New Delhi, India:

5. Langley RG, Gupta AK, Cherman AM, Inniss KA. Biologic therapeutics in the treatment of psoriasis. Part 1: review. J Cutan Med Surg. 2007; 11:99-122.

6. Nwabudike LC. Psoriasis and homeopathy. Proc Rom Acad Series B. 2011; 3:237-42.

7. Nwabudike LC. Palmar and plantar psoriasis and homeopathy - Case reports. Our Dermatol Online. 2017; 8(1):66-69. Submission: 13.04.2016; Acceptance: 27.07.2016 